\title{
Alkali-Activated Slag cement: Alternative Adhesives for CFRP Sheets Bonded to Concrete at Elevated Temperatures
}

\author{
Jing Zhu ${ }^{1,2 *}$, Wenzhong Zheng ${ }^{3}$, Lili Xie ${ }^{2}$, Ning Ren ${ }^{1}$, Yuxuan Zhang ${ }^{1}$ and Yongxin Zhang ${ }^{1}$ \\ ${ }^{1}$ College of Civil Engineering and Architecture, Harbin University of Science and Technology, Harbin 150080, China \\ ${ }^{2}$ Key Laboratory of Earthquake Engineering and Engineering Vibration, Institute of Engineering Mechanics, China \\ Earthquake Administration, Harbin 150080, China \\ ${ }^{3}$ Key Lab of Structures Dynamic Behavior and Control of the Ministry Education, Harbin Institute of Technology, Harbin \\ 150090, China
}

\section{Corresponding Author Email: zhujing@hrbust.edu.cn}

\section{ABSTRACT}

The properties and microstructures of alkali-activated slag cement (AASC) exposed to $20 \sim 1200^{\circ} \mathrm{C}$ were probed in this paper. The aim is to develop an eco-friendly fireproof high-strength adhesive with an optimum ratio and evaluate its usability for CFRP sheets bonded to concrete. The blast furnace slag and fly ash were employed as source materials (activated by potassium silicate, $\mathrm{NaOH}$ and Portland cement). The effects of slag content, activator nature and heating temperature on the compressive or bond properties were analyzed. The microstructures of the AASC exposed to different high temperatures were studied by two different techniques, including SEM and XRD analyses. The effects of temperature on the mechanical properties of AASC were first rising then descending, and the basic reason for the degradation of macromechanical properties is the deterioration of AASC microstructure. It is proved that AASC has comparable reinforcing effects as those of organic epoxy matrix.
\end{abstract}

Keywords: Alkali-activated slag, CFRP, high temperature, mechanical properties, microstructure Received: June-11-2020, Accepted: July-11-2020, https://doi.org/10.14447/jnmes.v23i3.a03

\section{INTRODUCTION}

The concrete structures strengthened with CFRP sheets usually use epoxy resins as adhesives. However, the resins lose the reinforcing effects at $60^{\circ} \mathrm{C} \sim 82^{\circ} \mathrm{C}$, which limits their applications at elevated temperatures. Recently, the alkaliactivated slag cement (AASC) have demonstrated great potential for overcoming this difficulty. Many researchers have proved that AASC is a high-temperature-resistant inorganic matrix for reinforced concrete (RC) enhanced by fiber- reinforced polymer (FRP) [1, 2].

From several points of view, it would be very beneficial if the organic adhesive could be replaced by AASC, which makes the utmost of by-product and industrial waste materials [3-5]. Inorganic adhesives (e.g., mineral-based bonding agents and cement-based adhesives) compared with organic adhesives have become popular [6-9]. The AASC is used to immobilize noxious substance [10-12] and some papers probe its strength, hydration or microstructure [13,14]. However, the literature information concerning the use of AASC instead of an organic one is very limited [15].

Producing cement creates a mass of carbon dioxide [16-18]. Hence, the fireproof adhesives with no cement or reducing the cement content have become research hot spot recently. In this study, blast furnace slag was adopted as an alternative of cement to produce AASC, and the purpose is to develop a high-temperature-resistant inorganic matrix for $\mathrm{RC}$ enhanced by FRP [19-22].

\section{RESEARCH AREA AND DATA}

\subsection{Fine aggregates}

Blast-furnace slag (BFS) could be classified as Grade S95 by GB/T 18046-2008 from the Ansteel Co. Ltd., China. The specific gravity of BFS was $2.87 \mathrm{~g} / \mathrm{cm}^{3}$. Fly ash (FA) Grade 1 as specified in GB/T 1596-2005 was collected from a power plant in the Heilongjiang province of China. The specific gravity was $2.36 \mathrm{~g} / \mathrm{cm}^{3}$. The BFS and FA were used as the fine aggregates in order to optimize the AASC. Fine aggregates and ordinary Portland cement (OPC) are shown in Table 1.

\subsection{Activators}

The fine aggregates were activated by potassium silicate solution (PS), sodium hydroxide $(\mathrm{NaOH})$, and OPC mixed with sodium carbonate $\left(\mathrm{Na}_{2} \mathrm{CO}_{3}\right)$, respectively. The density and modulus silicate ratio (Ms) of Grade I PS were 1.465 $\mathrm{g} / \mathrm{cm}^{3}$ and 1.76 (where $\mathrm{Ms}=\mathrm{n}, \mathrm{K}_{2} \mathrm{O} \cdot \mathrm{nSiO}_{2}, \mathrm{~K}_{2} \mathrm{O}=15.98 \%$, $\mathrm{SiO}_{2}=28.15 \%$ ), respectively. PS was used without any modification, when the effects of activator type on compressive strength of AASC were evaluated. But the $\mathrm{NaOH}$ (analytical reagent grade) needed to be attenuated with water to $14 \mathrm{M}$ concentration before using it. In addition, OPC (referred in Table 1) was used for a main activator and $\mathrm{Na}_{2} \mathrm{CO}_{3}$ was added for an auxiliary activator. 


\subsection{Bond Materials}

A water/ binder ratio 0.40 concrete cubes with $100 \mathrm{~mm}$ length were probed in bond tests. According to JG/T 167-
2004, UT70-20 and UT70-30 CFRP sheets (Toray, Japan) were chosen to bond concrete, and basic parameters of CFRP sheets are as shown in Table 2.

Table 1. Fine aggregates and OPC (wt. \%)

\begin{tabular}{ccccccccc}
\hline Materials & $\mathrm{SiO}_{2}$ & $\mathrm{Al}_{2} \mathrm{O}_{3}$ & $\mathrm{CaO}$ & $\mathrm{Fe}_{2} \mathrm{O}_{3}$ & $\mathrm{SO}_{3}$ & $\mathrm{MgO}$ & $\mathrm{TiO}_{2}$ & $\mathrm{LOI}^{\mathrm{a}}$ \\
\hline $\mathrm{BFS}$ & 33.70 & 14.40 & 41.70 & 0.37 & 0.40 & 6.40 & 1.10 & 0.39 \\
FA & 57.60 & 30.80 & 3.00 & 4.80 & 1.30 & 1.70 & - & 0.20 \\
OPC & 21.40 & 5.45 & 64.48 & 3.50 & 2.58 & 1.46 & 0.58 & 2.51 \\
\hline
\end{tabular}

Table 2. Basic parameters of CFRP sheets

\begin{tabular}{cccccc}
\hline Type & $\begin{array}{c}\text { Surface density } \\
\left(\mathrm{g} / \mathrm{m}^{2}\right)\end{array}$ & $\begin{array}{c}\text { sheet ply } \\
(\mathrm{mm})\end{array}$ & $\begin{array}{c}\text { strength of extension } \\
(\mathrm{MPa})\end{array}$ & $\begin{array}{c}\text { Modulus of elasticity } \\
(\mathrm{GPa})\end{array}$ & $\begin{array}{c}\text { Ultimate strain } \\
(\%)\end{array}$ \\
\hline CFRP sheet (UT70-20) & 200 & 0.111 & 4114 & 243 & 1.72 \\
CFRP sheet (UT70-30) & 300 & 0.167 & 4125 & 244 & 1.71 \\
\hline
\end{tabular}

\subsection{Mix proportion}

2.4.1. Effects of fine aggregates and activators on compressive properties of AASC

According to the previous research, the types of fine aggregates and alkaline activators play key roles in determining optimal mixtures of the components of AASC [5]. Therefore, potassium silicate $\left(\mathrm{K}_{2} \mathrm{O} \cdot \mathrm{nSiO}_{2}\right), \mathrm{NaOH}$, and OPC mixed with $\mathrm{Na}_{2} \mathrm{CO}_{3}$ were used as alkaline activators (Table 3 ). fine aggregates having $100 \% \mathrm{BFS}$, or $40 \% \mathrm{FA}$ and $60 \% \mathrm{BFS}$ were considered in this study. The alkaline activator to raw material ratios of $0.08,0.10$, and 0.12 were evaluated (where OPC and $\mathrm{Na}_{2} \mathrm{CO}_{3}$ to raw material ratios were $0.08,0.10$, and 0.12 ; and 0.02 , respectively. $\mathrm{Na}_{2} \mathrm{CO}_{3}$ was used to improve the activation effect of OPC).

Table 3. Factors and values tested

\begin{tabular}{|c|c|c|c|c|c|c|}
\hline \multirow{4}{*}{ Factor } & \multicolumn{3}{|c|}{$\mathrm{A} F / \mathrm{B}$ ratio of 0.00} & \multicolumn{3}{|c|}{$\mathrm{A} F / \mathrm{B}$ ratio of 0.67} \\
\hline & Grad & Grad & Grad & Grad & Grad & Grad \\
\hline & $\mathrm{e}$ & $\mathrm{e}$ & $\mathrm{e}$ & $\mathrm{e}$ & $\mathrm{e}$ & $\mathrm{e}$ \\
\hline & $\mathrm{a}$ & $\mathrm{b}$ & $\mathrm{c}$ & $\mathrm{d}$ & $\mathrm{e}$ & $\mathrm{f}$ \\
\hline $\begin{array}{c}\mathrm{A}:\left(\mathrm{K}_{2} \mathrm{O} \cdot \mathrm{nSiO}_{2}\right) / \text { fine aggregates ratio } \\
\mathrm{B}: \mathrm{NaOH} / \text { fine aggregates ratio } \\
\mathrm{C}:\left(\mathrm{OPC}+\mathrm{Na}_{2} \mathrm{CO}_{3}\right) / \text { fine aggregates ratio }\end{array}$ & 0.08 & 0.10 & 0.12 & 0.08 & 0.10 & 0.12 \\
\hline
\end{tabular}

2.4.2. Effects of activator nature on compressive and bond properties of AASC

Optimal mixtures related to strength and workability were further investigated on the factors as following: Ms, PS to BFS ratio $(\mathrm{P} / \mathrm{B})$, and water (where the water comes from the PS and tap water (TW)) to BFS ratio (W/B). Ms within the range of 0.8-2.4 was firstly considered, while maintaining constant proportions of other components (i.e. $\mathrm{P} / \mathrm{B}$ and $\mathrm{W} / \mathrm{B}$ ratios of
0.12 and 0.35 , respectively). In general, the PS with small Ms was made by addition of $\mathrm{NaOH}$. Here, the adjusted PS should be dissipated the excess heat. Besides, $\mathrm{P} / \mathrm{B}$ ratios of $0.08-0.22$ were investigated (where Ms of $\mathrm{PS}$ and $\mathrm{W} / \mathrm{B}$ ratio are 1.0 and 0.35 , respectively). Finally, W/B ratios of 0.32-0.48 used for the AASC mixture trials were tested to obtain workable mixes (where Ms and $\mathrm{P} / \mathrm{B}$ ratio are 1.0 and 0.12 , respectively). Table 4 indicates the details of mixes tested.

Table 4. The details of mixes tested

\begin{tabular}{|c|c|c|c|c|c|c|c|}
\hline \multirow[t]{2}{*}{ Type } & \multirow[t]{2}{*}{ Ms } & \multirow[t]{2}{*}{$\mathrm{P} / \mathrm{B}$} & \multirow[t]{2}{*}{$\mathrm{W} / \mathrm{B}$} & \multicolumn{4}{|c|}{ Unit weight $\left(\mathrm{kg} / \mathrm{m}^{3}\right)$} \\
\hline & & & & BFS & PS & $\mathrm{NaOH}$ & TW \\
\hline M8P12W35 & 0.8 & & & & 137.28 & 45.74 & 193.04 \\
\hline M10P12W35 & 1.0 & & & & 153.12 & 36.66 & 186.24 \\
\hline M12P12W35 & 1.2 & 0.12 & & & 166.00 & 29.35 & 180.64 \\
\hline M16P12W35 & 1.6 & & & & 185.47 & 18.29 & 172.24 \\
\hline M20P12W35 & 2.0 & & & & 199.44 & 10.84 & 166.24 \\
\hline M24P12W35 & 2.4 & & & & 210.00 & 4.28 & 161.68 \\
\hline M10P8W35 & & 0.08 & 0.35 & & 102.09 & 24.44 & 217.47 \\
\hline M10P10W35 & & 0.10 & & & 127.61 & 30.55 & 201.83 \\
\hline M10P14W35 & & 0.14 & & 800 & 178.66 & 42.77 & 170.57 \\
\hline M10P16W35 & & 0.16 & & & 204.18 & 48.88 & 154.94 \\
\hline M10P18W35 & & 0.18 & & & 229.71 & 54.99 & 139.30 \\
\hline M10P20W35 & 1.0 & 0.20 & & & 255.23 & 61.10 & 123.67 \\
\hline M10P22W35 & & 0.22 & & & 280.75 & 67.21 & 108.04 \\
\hline M10P12W32 & & & 0.32 & & 153.17 & 36.67 & 162.14 \\
\hline M10P12W38 & & & 0.38 & & 153.17 & 36.67 & 210.19 \\
\hline
\end{tabular}




\begin{tabular}{|c|c|c|c|c|c|}
\hline M10P12W42 & 0.12 & 0.42 & 153.17 & 36.67 & 242.24 \\
\hline M10P12W45 & & 0.45 & 153.17 & 36.67 & 266.24 \\
\hline M10P12W48 & & 0.48 & 153.17 & 36.67 & 290.27 \\
\hline
\end{tabular}

A workable mix (M10P12W35) was selected as the optimal mixtures of AASC, because it showed higher compressive and bond strengths among original eighteen mixes.

\subsection{CFRP sheets and concrete}

\subsubsection{AASC and OPC control samples}

Fine aggregates (BFS alone or mixed with $\mathrm{FA}$ ) and alkaline activators (PS, $\mathrm{NaOH}, \mathrm{OPC}$ mixed with $\mathrm{Na}_{2} \mathrm{CO}_{3}$ ) were mixed for $1 \mathrm{~min}$. Then, TW was poured into the pan, and the mixture was stirred about $6 \mathrm{~min}$, and the mixture was set aside for use.

The samples of AASC and OPC were $40 \times 40 \times 160 \mathrm{~mm}$ prisms, and the samples of OPC with a W/B of 0.25 were used as the contrast samples. The curing condition of samples was atmospheric temperature and $95 \% \mathrm{RH}$ (relative humidity of atomsphere). The demolded samples were stored in $50 \% \mathrm{RH}$ before testing them.

\subsubsection{Concrete and double shear samples}

Concrete cubes with dimensions of $100 \times 100 \times 100 \mathrm{~mm}$ and two different types of CFRP sheets were used for double shear tests (Table 2). The bonding procedure was conducted according to ACI code and China code to obtain the optimal bond quality. But only minor changes need to be taken, that is, the CFRP sheets should be pressed into a groove filled with fresh AASC for approximately $15 \mathrm{~min}$, which led to higher density. Then, the CFRP sheets (droplet side down) should be bonded on the concrete samples. Entrapped bubbles between layers should be squeezed out using a small plastic scraper. The thickness of adhesive layer was varied over the range 2 to $3 \mathrm{~mm}$. The curing condition of reinforced samples was atmospheric temperature and $50 \% \mathrm{RH}$. The AASC could be used as primer, putty filler, saturating resin, adhesive and protective coatings of the CFRP sheets.

\section{TESTING PROGRAM}

\subsection{Mechanical properties}

The mechanical properties of the AASC samples was tested referring to GB/T 17671-1999. Three samples were assessed in each group. A sample was broken into two halves (where flexural strengths of samples can be obtained), and they were tested on casting surfaces. Based on GB 50367-2006, the compressive strengths of the various mixes should not be lower than $70 \mathrm{MPa}$. The setting times of AASC samples were measured with a Vicat apparatus.

\subsection{Bond properties}

Double shear tests were adopted due to their simplicity [12, 23]. 378 bond samples were assessed on basic parameters of CFRP sheets and adhesive properties in bond tests, and the construction technology was kept consistent. The values reported were averages of the results obtained for three samples. The CFRP sheets were bonded to the concrete cubes with AASC and epoxy resin to compare their bond strength and failure mode.

\subsection{Microstructural analysis}

The Quanta200 scanning electron microscope (SEM) provided by PhiliPs-FEI Company and XRD provided by Rigaku Company in Japan were used in this study. The samples for SEM observations were determined for mixture M10P12W35 and OPC. The samples were broken into pieces and immersed for $24 \mathrm{~h}$ in anhydrous ethanol to terminate their hydration. Then, they were dried for approximately $3 \mathrm{~h}$ and coated with $200 \AA$ of gold. Finally, the coated samples were shrouded and transferred under vacuum to the cryostage of the SEM, examined and photographed.

\subsection{Residual compressive behavior}

The residual compressive strength and weight loss of AASC exposed to $20 \sim 1200^{\circ} \mathrm{C}\left(200,400,600,800,1000\right.$ and $\left.1200^{\circ} \mathrm{C}\right)$ were investigated, and the heating rate and load rate were $2.5^{\circ} \mathrm{C} / \mathrm{min}$ and $20 \mathrm{MPa} / \mathrm{min}$, respectively. Three samples were studied for every measurement. The samples were characterized using SEM. The XRD analysis was used to verify whether or not $\mathrm{CSH}$ gel after exposure to elevated temperatures had been replaced by akermanite.

\section{ANALYSIS RESULTS}

\subsection{Mechanical properties}

For the same F/B ratio ( 0 and 0.67 ), the mixtures containing higher $\left(\mathrm{K}_{2} \mathrm{O} \cdot \mathrm{nSiO}_{2}\right) /$ fine aggregates ratio (A3) produced higher compressive strength $(85.59 \mathrm{MPa})$ than that with lower $\mathrm{NaOH} /$ fine aggregates ratio $(\mathrm{B} 1)$ and $\left(\mathrm{OPC}+\mathrm{Na}_{2} \mathrm{CO}_{3}\right) /$ fine aggregates ratio $(\mathrm{C} 1)$. It could be observed that the mix A3 with $\left(\mathrm{K}_{2} \mathrm{O} \cdot \mathrm{nSiO}_{2}\right) /$ fine aggregates ratio of 0.12 showed the highest compressive strength. Therefore, the optimal mixture A3 was identified. The BFS and PS were confirmed as the effective components for adhesive and used in this study. The fine aggregate details were showed in Figure. 1a, $\mathrm{b}$.

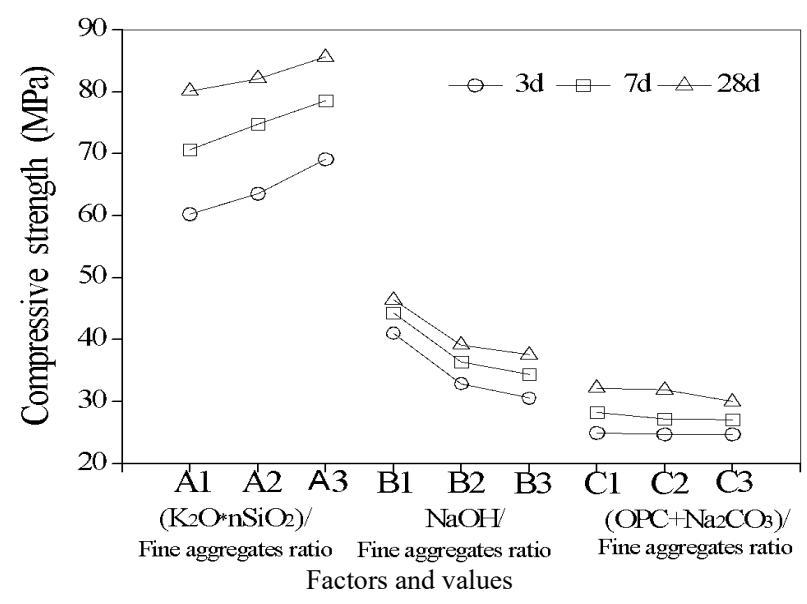

(a) The fine aggregate without FA 


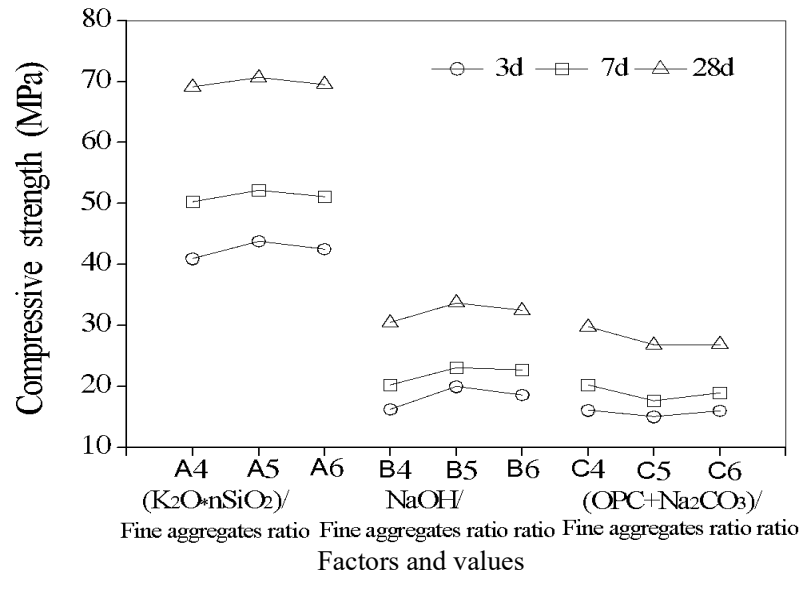

(b) The fine aggregate with $\mathrm{F} / \mathrm{B}$ ratio of 0.67

Figure 1. Effect of raw materials on compressive strength

It was proven that $\mathrm{P} / \mathrm{B}$ ratio, $\mathrm{Ms}$ and $\mathrm{PS}$ effected on compressive strength of AASC, and the specific situation was shown in Table 5. The compressive strengths of AASC decreased with the increase of Ms. However, the Ms of the PS has a reasonable range as not lower than 1.0. Thus, 1.0 was chosen as workable Ms. In addition, the contents of alkaline solutions decreased with the increase of compressive strength, but the mixture with $\mathrm{P} / \mathrm{B}$ ratio of 0.12 (M10P12W35) developed the greatest strength. Therefore, the $\mathrm{P} / \mathrm{B}$ ratio was kept constant at 0.12 .

Experimental results showed that the $\mathrm{W} / \mathrm{B}$ ratio is the crucial factor on the mechanical properties of mixture and the wettability of CFRP sheets. If the water is insufficient (i.e. $\mathrm{W} / \mathrm{B}$ ratio is 0.32 ), the AASC becomes sticky and its initial setting time is relatively short $(30 \mathrm{~min})$, which does not facilitate wetting of CFRP sheets. Thus, the availability of sufficient water (i.e. W/B ratio is equal to or larger than 0.35 ) is a key ingredient in impregnating the CFRP sheets. The increase of the amount of water increases its initial time of coagulation (40 $\mathrm{min}$ ) and final time of coagulation (75 min). The optimal mixtures were: mix M10P12W32 for high compressive strength, and mix M10P12W35 showed only moderate strength, but better workability than the former one. Moreover, the average compressive strength of the optimal mixture (M10P12W35) is $90.16 \mathrm{MPa}$ at 28 days, which reaches the expected value $70 \mathrm{MPa}$. The compressive and flexural strengths of AASC at 28 days are shown in Figure 2 and Figure 3.

Table 5. Mechanical properties of AASC

\begin{tabular}{lccc}
\hline Type of mixture & \multicolumn{3}{c}{ Compressive strength of AASC } \\
& 3 d & $7 \mathrm{~d}$ & $28 \mathrm{~d}$ \\
\hline M8P12W35 & 73.33 & 82.02 & 95.03 \\
M10P12W35 & 72.67 & 80.69 & 90.16 \\
M12P12W35 & 68.65 & 76.22 & 83.14 \\
M16P12W35 & 51.48 & 57.85 & 76.32 \\
M20P12W35 & 49.42 & 54.87 & 71.07 \\
M24P12W35 & 44.79 & 49.73 & 62.68 \\
M10P8W35 & 63.42 & 70.37 & 78.69 \\
M10P10W35 & 68.01 & 75.52 & 84.36 \\
M10P14W35 & 69.72 & 77.41 & 86.50 \\
M10P16W35 & 66.64 & 74.03 & 82.68 \\
M10P18W35 & 63.30 & 68.84 & 78.53 \\
M10P20W35 & 48.87 & 54.27 & 60.64 \\
M10P22W35 & 42.70 & 47.41 & 52.97 \\
M10P12W32 & 76.42 & 84.85 & 94.81 \\
M10P12W38 & 41.37 & 58.69 & 68.96 \\
M10P12W42 & 58.52 & 70.28 & 80.88 \\
M10P12W45 & 56.53 & 62.66 & 65.74 \\
M10P12W48 & 40.72 & 45.14 & 47.36 \\
\hline
\end{tabular}

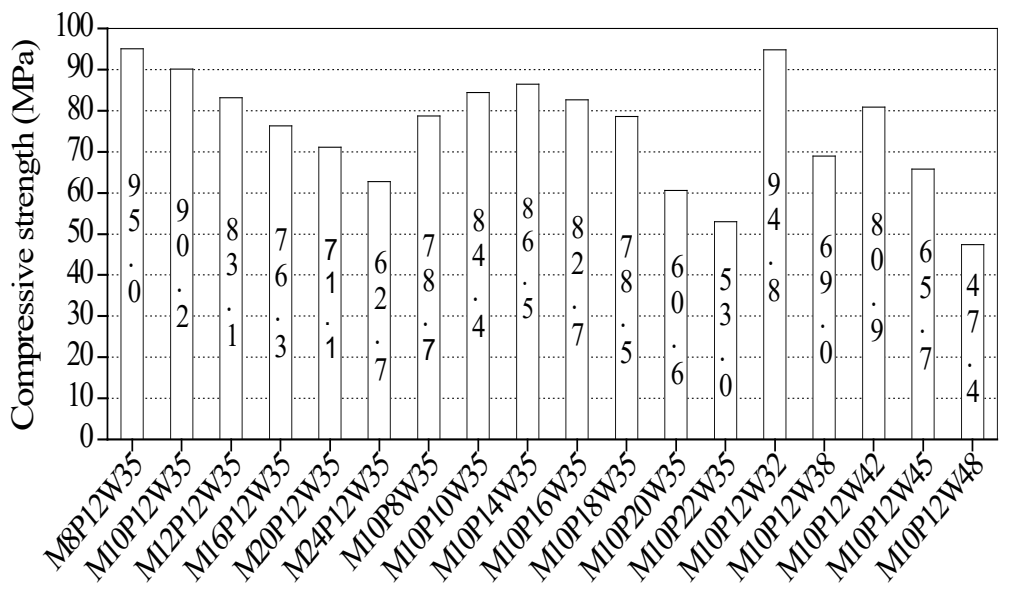

Trial mixes

Figure 2. Compressive strength of the trial mixes at 28 days 


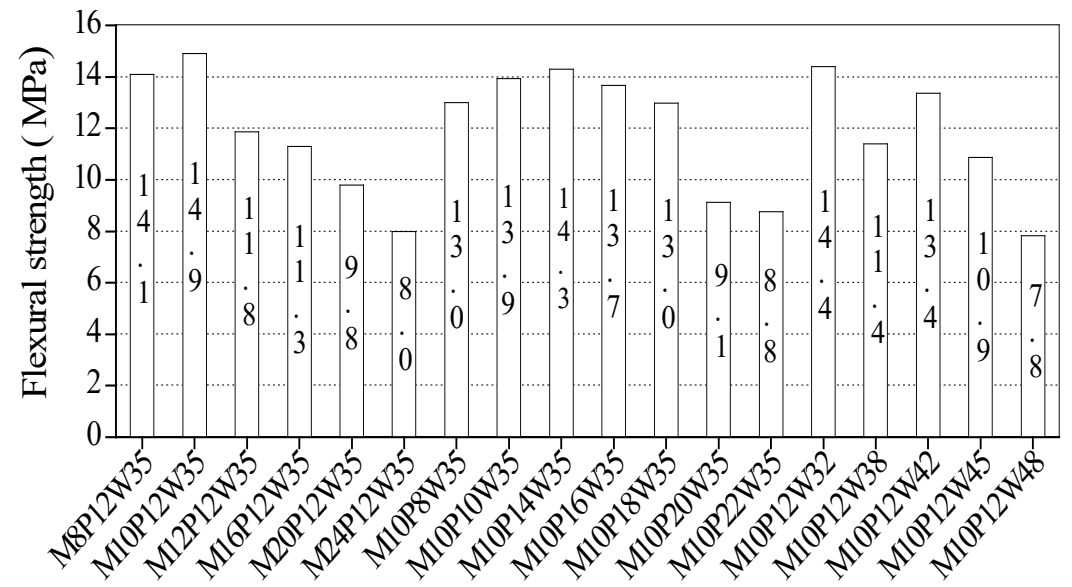

Trial mixes

Figure 3. Flexural strength of the trial mixes at 28 days

\subsection{Bond properties}

\subsubsection{Bond strength of AASC}

The bond tests were performed at $20 \pm 2{ }^{\circ} \mathrm{C}$, CFRP UT70-30 ultimately occurred shear debonding but CFRP UT70-20 occurred fiber fracture, and the results were shown in Table 6 and Figure 4. It is proven that there is greater tensile and bond strength of UT70-30 than those of UT70-20 (Figure 5). Thus, the bond strength and failure mode are governed by different factors like the concrete grade, the type of CFRP sheet, and the penetration of adhesive. On the basis of the above analyses, the mix (M10P12W35) with higher compressive strength (90.16 MPa), flexural strength (14.9 MPa) and bond strength $(1.51 \mathrm{MPa})$ was therefore chosen as the optimal mixture because of its excellent workability.

Table 6. Bond testing results of the trial mixes at 28 days

\begin{tabular}{ccccccc}
\hline Mixture type & \multicolumn{3}{c}{ CFRP sheet (UT70-20) } & \multicolumn{2}{c}{ CFRP sheet (UT70-30) } \\
& $3 \mathrm{~d}$ & $7 \mathrm{~d}$ & $28 \mathrm{~d}$ & $3 \mathrm{~d}$ & $7 \mathrm{~d}$ & $28 \mathrm{~d}$ \\
\hline M8P12W35 & 1.02 & 1.23 & 1.46 & 1.17 & 1.50 & 1.55 \\
M10P12W35 & 0.97 & 1.16 & 1.39 & 1.14 & 1.45 & 1.51 \\
M12P12W35 & 0.92 & 1.01 & 1.22 & 1.09 & 1.27 & 1.36 \\
M16P12W35 & 0.89 & 0.96 & 1.16 & 1.05 & 1.20 & 1.29 \\
M20P12W35 & 0.69 & 0.81 & 0.97 & 0.81 & 1.01 & 1.08 \\
M24P12W35 & 0.48 & 0.65 & 0.78 & 0.57 & 0.82 & 0.87 \\
M10P8W35 & 0.85 & 1.02 & 1.21 & 1.01 & 1.27 & 1.34 \\
M10P10W35 & 0.91 & 1.09 & 1.30 & 1.07 & 1.36 & 1.45 \\
M10P14W35 & 0.92 & 1.10 & 1.32 & 1.08 & 1.37 & 1.48 \\
M10P16W35 & 0.88 & 1.05 & 1.26 & 1.03 & 1.31 & 1.42 \\
M10P18W35 & 0.83 & 1.01 & 1.19 & 0.98 & 1.24 & 1.35 \\
M10P20W35 & 0.64 & 0.78 & 0.92 & 0.76 & 0.96 & 1.04 \\
M10P22W35 & 0.56 & 0.69 & 0.81 & 0.67 & 0.85 & 0.92 \\
M10P12W32 & 1.02 & 1.22 & 1.43 & 1.20 & 1.52 & 1.56 \\
M10P12W38 & 0.81 & 0.93 & 1.10 & 0.94 & 1.16 & 1.24 \\
M10P12W42 & 0.95 & 1.11 & 1.32 & 1.12 & 1.38 & 1.49 \\
M10P12W45 & 0.87 & 0.94 & 1.11 & 1.03 & 1.18 & 1.23 \\
M10P12W48 & 0.63 & 0.68 & 0.80 & 0.74 & 0.85 & 0.89 \\
\hline
\end{tabular}




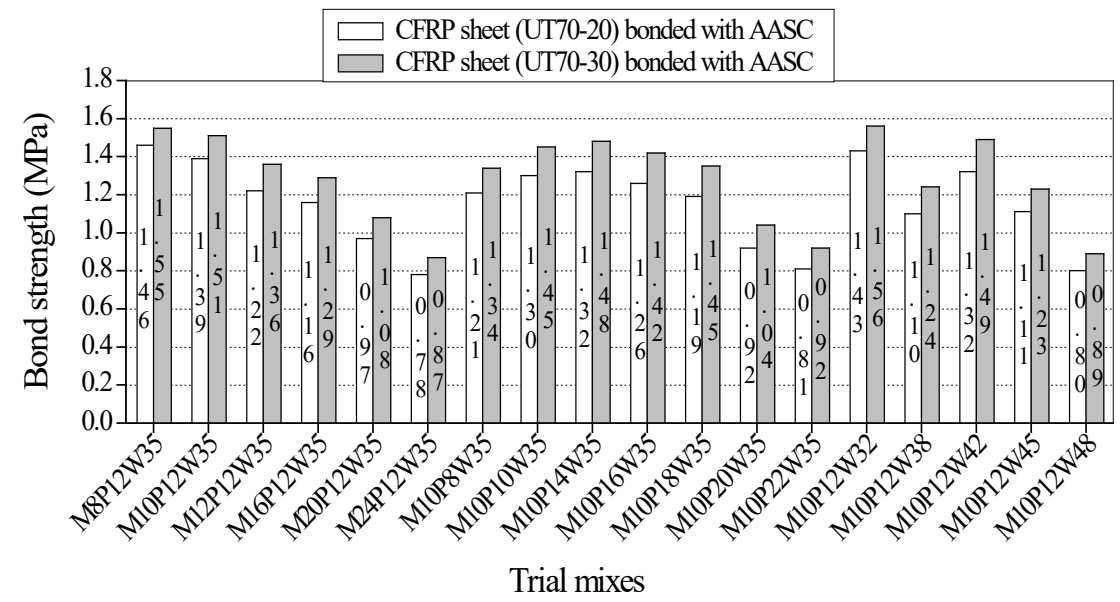

Figure 4. Bond strength of the trial mixes at 28 days

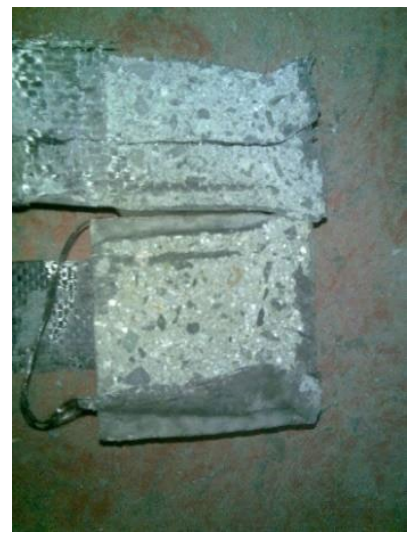

(a) CFRP sheet UT70-20

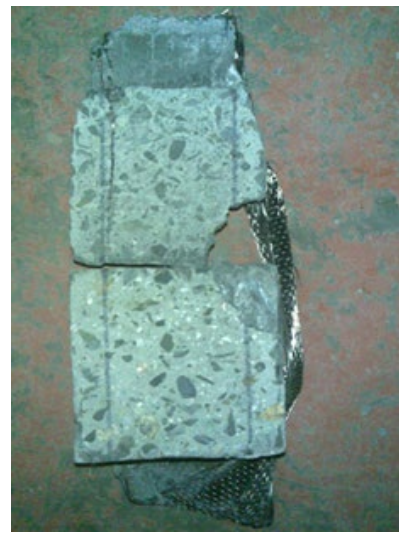

(b) CFRP sheet UT70-30

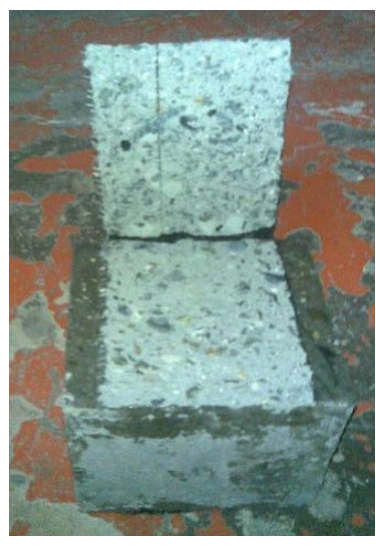

(c) CFRP sheet UT70-30

Figure 5. Debonding failure in concrete strengthened with (a) CFRP sheet (UT70-20) bonded with AASC, (b) CFRP sheet (UT70-30) bonded with AASC and (c) CFRP sheet UT70-30 bonded with epoxy adhesive

4.2.2. Comparison of the bond properties between AASC and epoxy adhesive

In double shear tests, the debonding failure in concrete was obtained, that is, concrete occurred fracture between the debonding interface. As shown in Figure 5, 2 to $4 \mathrm{~mm}$ thick concrete was debonded with CFRP sheet. Debonding concrete zone with visible aggregate was uneven. One of possible explanations could be a good penetration of AASC in the centre of the carbon fiber tow.

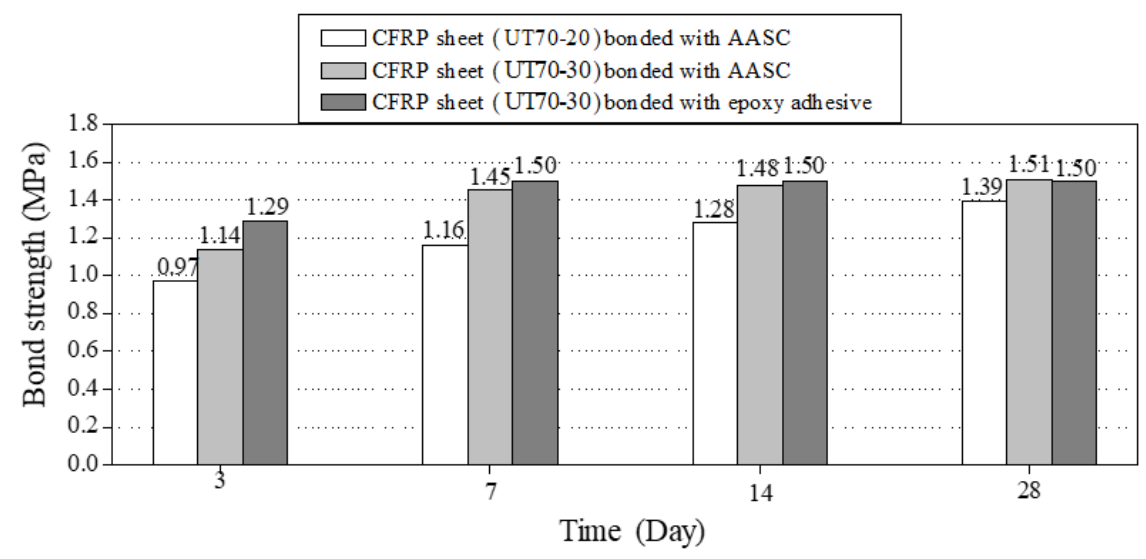

Figure 6. Bond strength between AASC and epoxy adhesive

Bond strength between AASC and epoxy adhesive was shown in Figure 6. The final bond strength is an average of three samples. The test results indicate that the bond strength of AASC varies with different CFRP types, and the AASC and epoxy adhesive have approximately similar bond strengths and failure mode. 


\subsection{Microstructural analysis}

Figure 7 shows the micrographs of AASC and OPC control samples. After 3 days of hydration, there was no phase separation remarkable, and the microstructure of AASC paste made up of an uniform gel in the SEM. After 7 days of hydration, the microstructure of AASC paste got denser, and the raw materials had fully reacted. Obviously, there were a large number of hydration products on the surface of the slag particles, indicating their formation by a dissolution and precipitation mechanisms at early ages [24]. After 28 days of hydration as reaction proceeded, the reaction was basically complete, and the gel had filled the space and gradually densified.

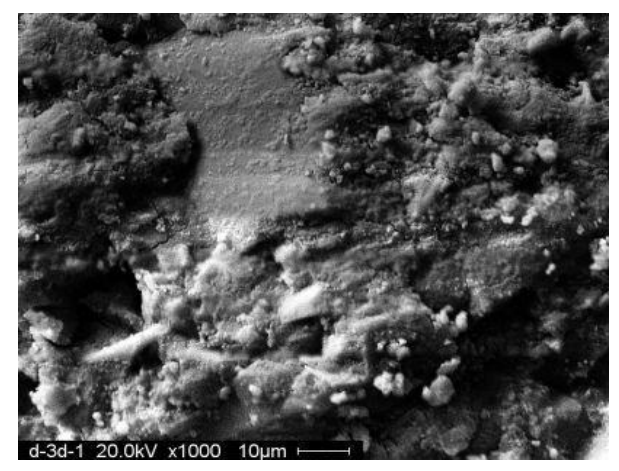

(a) AAS matrix (3 days)

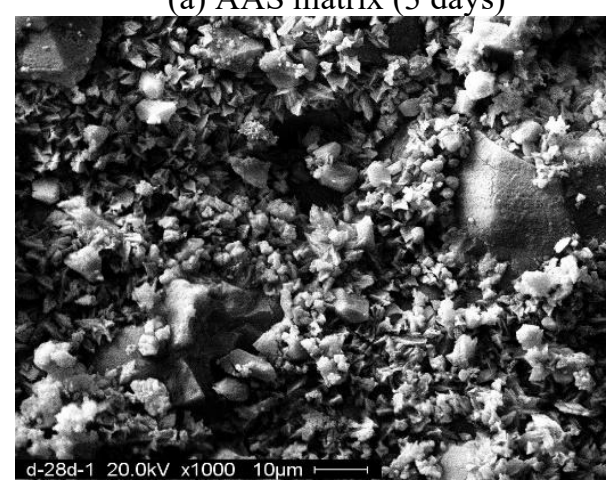

(c) AAS matrix (28 days)

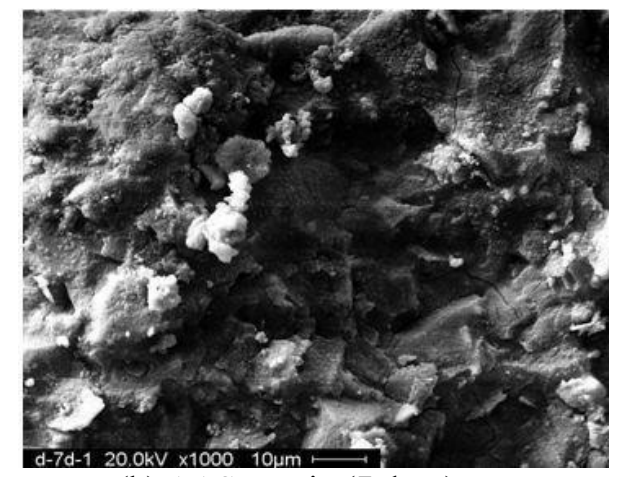

(b) AAS matrix (7 days)

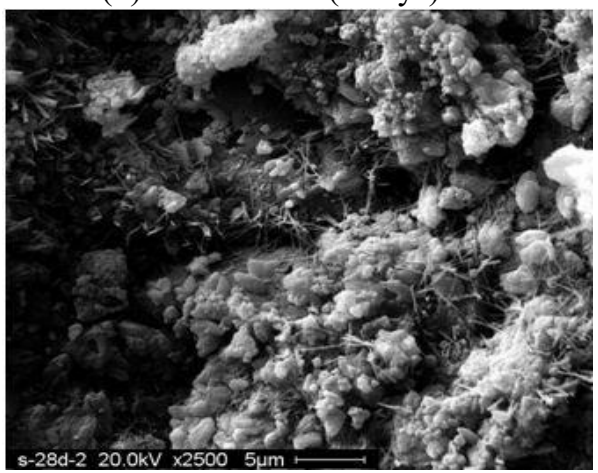

(d) OPC sample (28 days)

Figure 7. SEM images of AASC samples at (a) 3 days, (b) 7 days and (c) 28 days; (d) SEM image of OPC control sample at 28 days

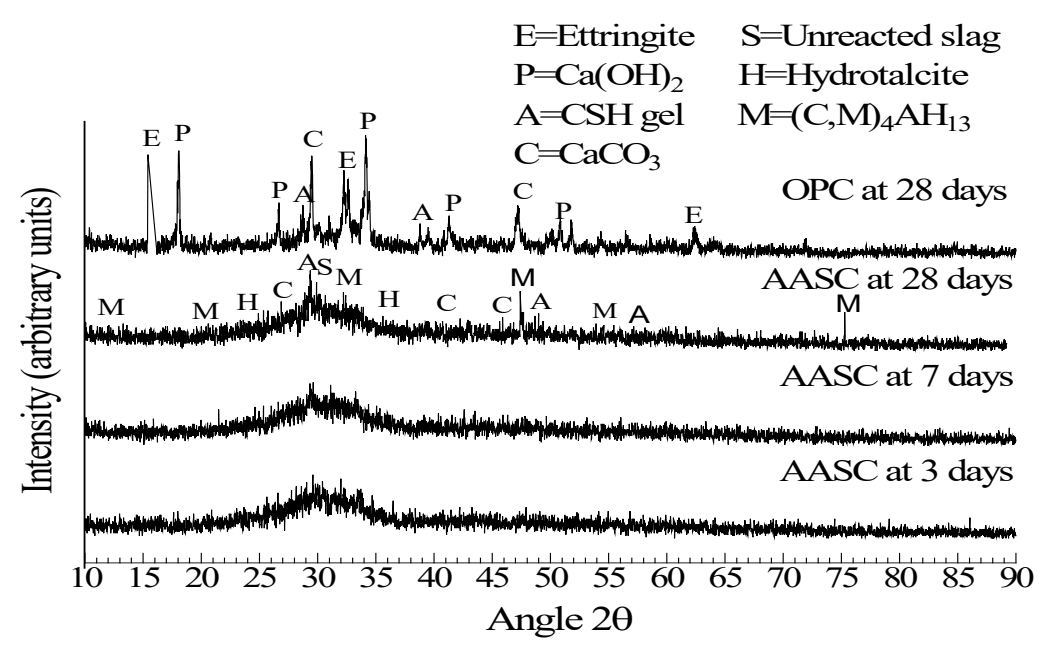

Figure 8. XRD patterns of AASC and OPC control samples with different ages

XRD patterns of AASC and OPC control specimens are presented in Figure 8. As shown in Figure 8, it is confirmed that the outcomes of AASC incorporate CSH-type hydration and $\mathrm{Mg}_{6} \mathrm{Al}_{2} \mathrm{CO}_{3}(\mathrm{OH})_{16} \cdot 4 \mathrm{H}_{2} \mathrm{O}$. Besides, The products of $\mathrm{OPC}$ include $\mathrm{Ca}_{6}\left[\mathrm{Al}(\mathrm{OH})_{6}\right]_{2}\left(\mathrm{SO}_{4}\right)_{3} \cdot 26 \mathrm{H}_{2} \mathrm{O}, \mathrm{Ca}(\mathrm{OH})_{2}, \mathrm{CaCO}_{3}$, and $(\mathrm{CaO})_{x} \cdot \mathrm{SiO}_{2} \cdot\left(\mathrm{H}_{2} \mathrm{O}\right)_{y}$. Therefore, the cementitious material in
AASC specimens is more denser than in OPC specimens, and more homogeneous with a vitreous aspect.

\subsection{Residual compressive behavior}

Figure 9 represents the 1, 3, 7, 14, 28, 50, 90, 120, 150 and 180 day strengths of the AASC investigated. The target 
strength of optimal mixture (M10P12W35) was 90.16MPa at 28 days. The early age strengths of AASC (1, 3 and 7 days strengths) are higher than that of OPC.

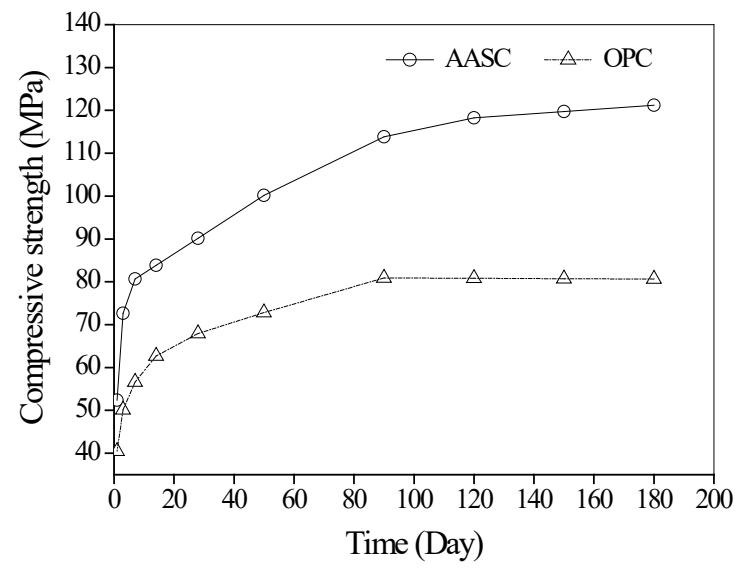

Figure 9. Compressive strengths of AASC and OPC control samples until 180 days after curing

Figure 10 shows the residual compressive strengths of AASC and OPC control samples after exposure to 20, 200, $400,600,800,1000$ and $1200^{\circ} \mathrm{C}$. Between 20 and $200^{\circ} \mathrm{C}$, the strength of AASC specimens increased $16 \%$. Between 400 and $600^{\circ} \mathrm{C}$, the strength increase is believed to be due to the further hydration processes. Between 600 and $800^{\circ} \mathrm{C}$ exposures, the compressive strength of AASC specimens decreased approximately $49 \%$. Furthermore, when the AASC specimens were exposed to 1000 and $1200^{\circ} \mathrm{C}$, the remaining strengths of AASC were $44 \%$ and $38 \%$, respectively. Results showed that the compressive strength of AASC increases at first, then decreases with the increasing temperatures.

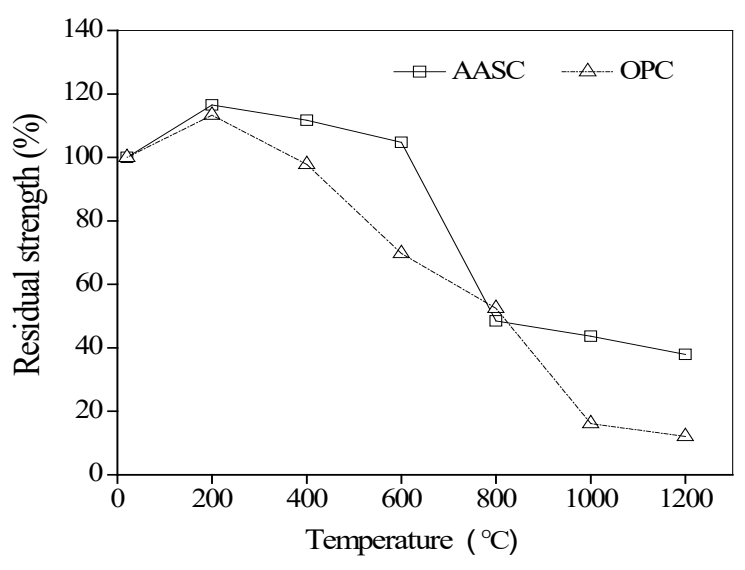

Figure 10. Residual compressive strengths of AASC and OPC control samples

\subsection{Microstructural analysis after exposure to elevated temperatures}

Figure 11 shows the change of the interior zone of AASC at $600^{\circ} \mathrm{C} \mathrm{SEM}$, it is shown there is not any changes in the phase composition at $600^{\circ} \mathrm{C} \mathrm{XRD} \mathrm{in} \mathrm{Figure} 12$. However, the products of AASC is $\mathrm{Ca}_{2} \mathrm{MgSi}_{2} \mathrm{O}_{7}$ at $800^{\circ} \mathrm{C} \mathrm{XRD}$. It is proven that the mechanical properties improvement begins at $800^{\circ} \mathrm{C}$ dramatically because of the changes in the phase composition of AASC.

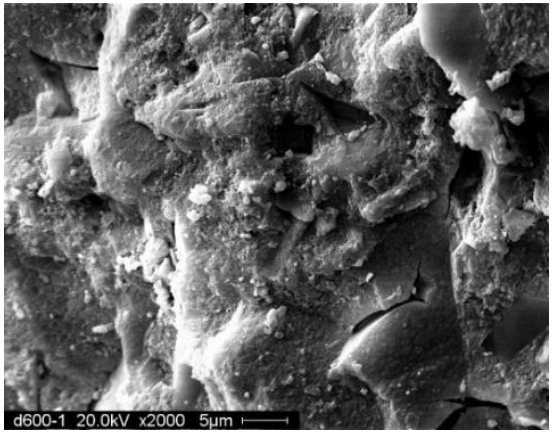

Figure 11. SEM picture of the AASC specimen after exposure to $600{ }^{\circ} \mathrm{C}$

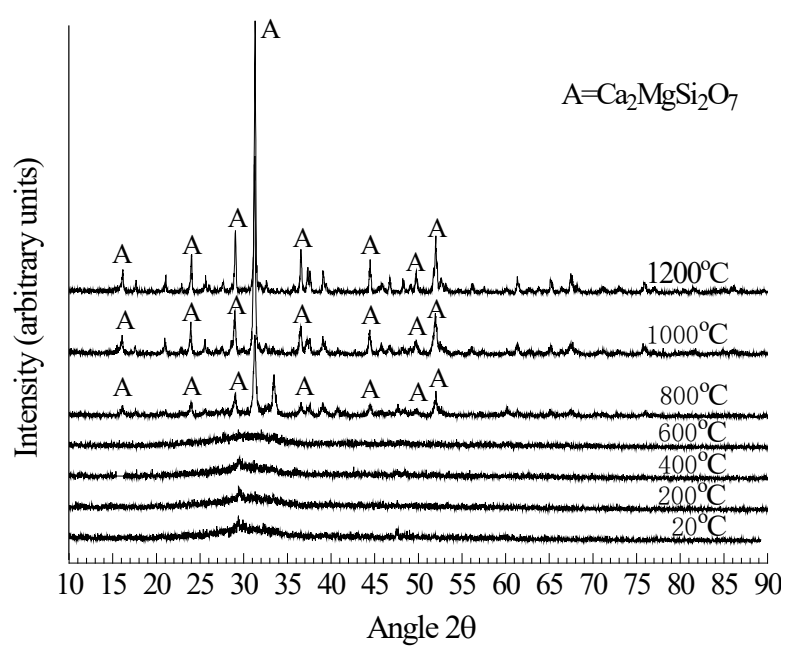

Figure 12. XRD analysis of the AASC samples after exposure to $20 \sim 1200{ }^{\circ} \mathrm{C}$

The basic reason for the degradation of macro-mechanical properties is the deterioration of AASC microstructure. As shown in Figure 13, the porosity increased markedly after exposure to $600^{\circ} \mathrm{C}$, and reached its maximum at $800^{\circ} \mathrm{C}$. Figure $14 \mathrm{a}$ shows the relatively compact structure and different porosity of AASC as compared to the OPC (Figure 14b), and indicates that the new binder phase of AASC after exposure to $800{ }^{\circ} \mathrm{C}$ is different properties with the original $\mathrm{CSH}$ gel after exposure to $600{ }^{\circ} \mathrm{C}$ (Figure 11).

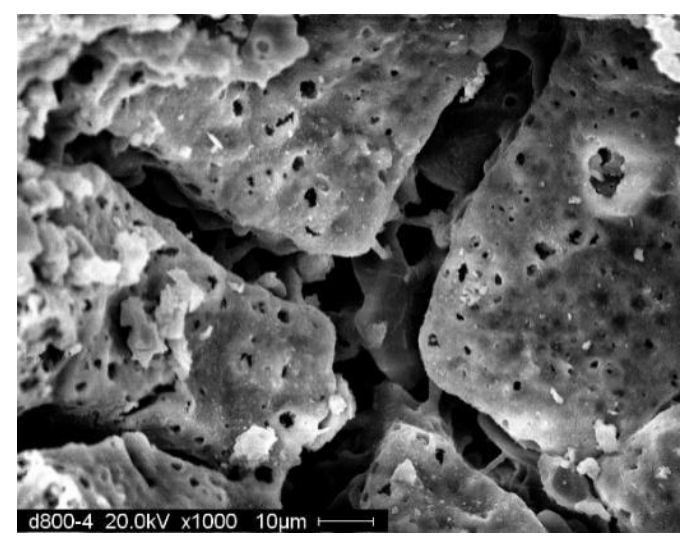

Figure 13. SEM picture of the AASC specimen after exposure to $800^{\circ} \mathrm{C}$ 


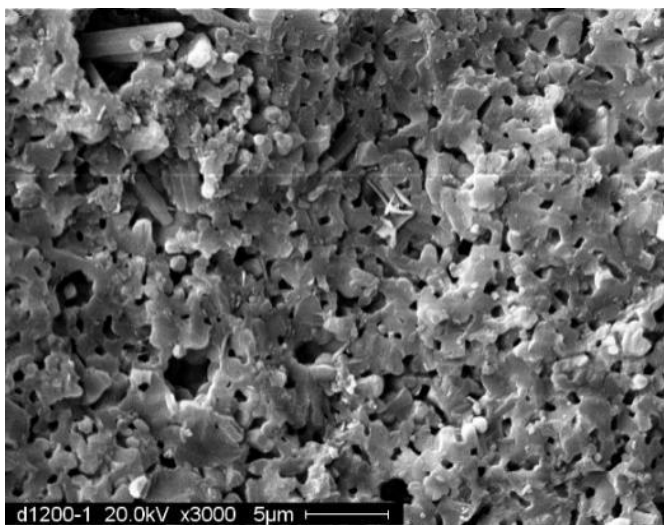

(a) the AASC sample

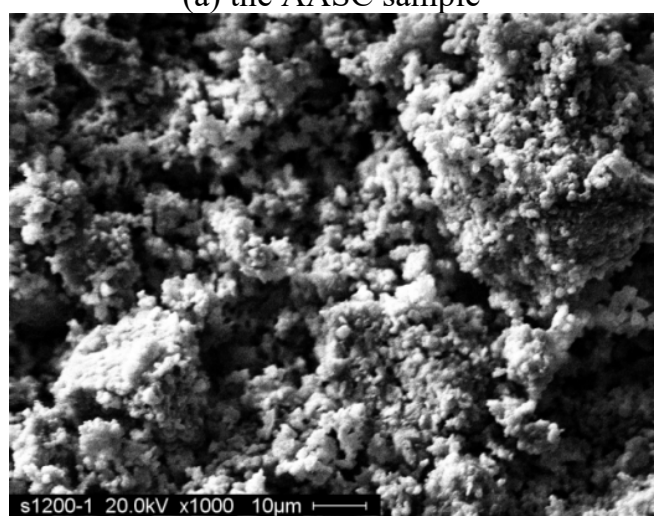

(b) the OPC control sample

Figure 14. SEM images after exposure to $1200^{\circ} \mathrm{C}$

\subsection{Weight loss}

As the temperature increases, the surface color of AASC sample becomes darker at first, and then becomes lighter (Figure 15), meanwhile the weight loss increases gradually. Figure 16 represents the weight changes $(\%)$ of the AASC and OPC control specimens after exposure to $20 \sim 1200{ }^{\circ} \mathrm{C}$. The weight of specimens change from 520 to $525 \mathrm{~g}$. Before $180^{\circ} \mathrm{C}$, the water vapor and thermal energy are more likely to overflow, thus the corresponding weight loss is larger. Therefore, the products of AASC include denser structure akermanite, which improves the thermal stability of the AASC.

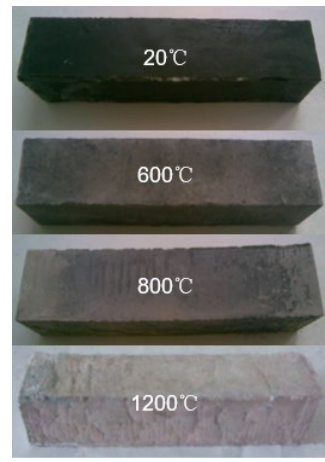

Figure 15. Appearance and color change of AASC samples exposed to high temperatures

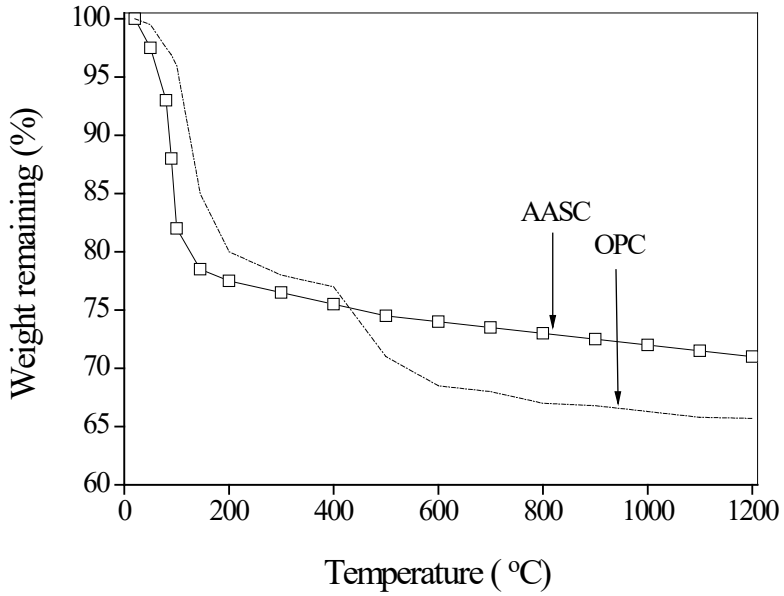

Figure 16. Weight changes (\%) of the AASC and OPC control specimens after exposure to $20 \sim 1200{ }^{\circ} \mathrm{C}$

\section{CONCLUSIONS}

AASC has the thermal stability, and is an eco-friendly material. Through experimental research on the properties and microstructures of AASC exposed to $20 \sim 1200^{\circ} \mathrm{C}$, the following conclusions can be drawn.

1. One hundred percent BFS gave high compressive strength. Based on the effects of activator nature on the compressive or bond properties, the BFS and PS were confirmed as the effective components for the AASC, and the mix (M10P12W35) was the optimum mixture for CFRP sheets bonded to concrete at elevated temperatures.

2. Compared with the OPC, the AASC samples showed rapid hardening and higher early strength. In double shear tests, the improvement in bond properties of AASC was attributed to the adopted type of CFRP sheets as well as a good penetration of the AASC, which led to higher bonding strength. The bond properties of the optimal mix tested are comparable to those of epoxy adhesive.

3. The residual compressive strength of AASC increases at first, then decreases with the increasing temperatures. The basic reason for the degradation of macro-mechanical properties is the deterioration of AASC microstructure. After heating to $600^{\circ} \mathrm{C}$, the porosity began to increase significantly, reached its maximum at $800^{\circ} \mathrm{C}$. The AASC has the thermal stability, and the optimal AASC provides a more durable alternative to epoxy adhesive at elevated temperatures.

\section{ACKNOWLEDGMENT}

This research was supported by the National Natural Science Foundation of China (NO. 51508140), and the Natural Science Foundation of Heilongjiang (NO. LH2019E066), and the College Students' innovation and Entrepreneurship Project (NO. 202010214213). The authors would like to thank all the staff and technicians in the Lab of Structural and Seismic in Harbin University of Science and Technology for their kind assistance during the tests.

\section{REFERENCES}

[1] Zuda, L., Rovnaník, P., Bayer, P., Černý, R. (2007). Thermal properties of alkali-activated slag subjected to 
high temperatures. Journal of Building Physics, 30(4): 337-350. https://doi.org/10.1177/1744259106075234

[2] Guerrieri, M., Sanjayan, J., Collins, F. (2009). Residual compressive behavior of alkali-activated concrete exposed to elevated temperatures. Fire and Materials: An International Journal, 33(1): 51-62. https://doi.org/10.1002/fam.983

[3] Roy, D.M. (1999). Alkali-activated cements opportunities and challenges. Cement and concrete research, 29(2): 249-254. https://doi.org/10.1016/S00088846(98)00093-3

[4] Sathish, T., Chandramohan, D., Vijayan, V., Sebastian, P.J. (2019). Investigation on microstructural and mechanical properties of $\mathrm{Cu}$ reinforced with Sic composites prepared by microwave sintering process. Journal of New Materials for Electrochemical Systems, 22(1): 5-9. https://doi.org/10.14447/jnmes.v22i1.a02

[5] Shen, L.H., Wang, J.Y., Xu, S.L., Amoako-Atta, G. (2019). Fire resistance behavior of full-scale self-thermal insulation sandwich walls made of textile-reinforced concrete. International Journal of Heat and Technology, 37(1): 239-248. https://doi.org/10.18280/ijht.370129

[6] Zhu, J., Zheng, W.Z., Sneed, L.H., Huang, Y., Xu, C.H. (2019). Mechanical properties of plant fibers reinforced alkali-activated slag cementitious material at high temperature. Annales de Chimie - Science des Matériaux, 43(4): 249-255. https://doi.org/10.18280/acsm.430408

[7] Gantchenko, V., Renard, J. (2017) Characterization of an adhesive bonding. Arcan-Mines test and fracture mechanics results, Revue des Composites et des Matériaux Avancés, 27(3-4): 319-334. https://doi.org/10.3166/rcma.2017.00019

[8] Täljsten, B., Blanksvärd, T. (2007). Mineral-based bonding of carbon FRP to strengthen concrete structures. Journal of Composites for Construction, 11(2): 120-128. https://doi.org/10.1061/(ASCE)10900268(2007)11:2(120)

[9] Yu, D. (2017). Experimental study on anti-seismic property of inorganic polymer concrete short columns after high temperature, Annales de Chimie-Science des Matériaux, 41(3-4): 225-237. https://doi.org/10.3166/ACSM.41.225-237

[10] Deja, J. (2002). Immobilization of $\mathrm{Cr}^{6+}, \mathrm{Cd}^{2+}, \mathrm{Zn}^{2+}$ and $\mathrm{Pb}^{2+}$ in alkali-activated slag binders. Cement and Concrete Research, 32(12): 1971-1979. https://doi.org/10.1016/S0008-8846(02)00904-3

[11] Palomo, A., Palacios, M. (2003). Alkali-activated cementitious materials: Alternative matrices for the immobilisation of hazardous wastes: Part II. Stabilisation of chromium and lead. Cement and concrete research, 33(2): 289-295. https://doi.org/10.1016/S00088846(02)00964-X

[12] Brough, A.R., \& Atkinson, A. (2002). Sodium silicatebased, alkali-activated slag mortars: Part I. Strength, hydration and microstructure. Cement and concrete research, 32(6): 865-879. https://doi.org/10.1016/S00088846(02)00717-2
[13] Pacheco-Torgal, F., Castro-Gomes, J., Jalali, S. (2008). Alkali-activated binders: A review: Part 1. Historical background, terminology, reaction mechanisms and hydration products. Construction and Building Materials, 22(7): $1305-1314$. https://doi.org/10.1016/j.conbuildmat.2007.10.015

[14] Yang, K.H., Cho, A.R., Song, J.K., Nam, S.H. (2012). Hydration products and strength development of calcium hydroxide-based alkali-activated slag mortars. Construction and Building Materials, 29: 410-419. https://doi.org/10.1016/j.conbuildmat.2011.10.063

[15] Mathivanan, N.R., Babu, N.M., Kumar, K.V. (2018). Empirical study on twisting force using Taguchi doe technique during drilling of hybrid FRP laminate. Revue des Composites et des Materiaux Avances, 28(2): 277288. https://doi.org/10.3166/rcma.28.277-288

[16] Toutanji, H., Deng, Y. (2007). Comparison between organic and inorganic matrices for RC beams strengthened with carbon fiber sheets. Journal of Composites for Construction, 11(5): 507-513. https://doi.org/10.1061/(ASCE)10900268(2007)11:5(507)

[17] Shi, C., Roy, D., Krivenko, P. (2003). Alkali-activated cements and concretes. CRC press.

[18] Won, J.P., Kang, H.B., Lee, S.J., Kang, J.W. (2012). Eco-friendly fireproof high-strength polymer cementitious composites. Construction and Building Materials, 30: 406-412. https://doi.org/10.1016/j.conbuildmat.2011.12.034

[19] Komma, H.K.R., Nerella, R., Madduru, S.R.C. (2019). Art-of-review on CFRP wrapping to strengthen compressive and flexural behavior of concrete. Revue des Composites et des Matériaux Avancés, 29(3): 159163. https://doi.org/10.18280/rcma.290305

[20] Yao W.L., Jiang S.Y., Tao S., Fei W. (2018). Chloride diffusion analysis of reinforced concrete beam enhanced with externally bonded fibre reinforced polymer considering the presence of rebars and stirrups, International Journal of Heat and Technology, 36(2): 632-642. https://doi.org/ 10.18280/ijht.360228

[21] Wang, C.L., Zhao, G.F., Zheng, Y.C., Zhang, K.F., Ye, P.Y., Cui, X.W. (2019). Study on the preparation of high performance concrete using steel slag and iron ore tailings. Journal of New Materials for Electrochemical Systems, 22(4): 217-223. https://doi.org/10.14447/jnmes.v22i4.a07

[22] Teng, J.G., Chen, J.F., Smith, S.T., Lam, L. (2002). FRP: strengthened RC structures, 266.

[23] Escalante-García, J.I., Fuentes, A.F., Gorokhovsky, A., Fraire-Luna, P.E., Mendoza-Suarez, G. (2003). Hydration products and reactivity of blast-furnace slag activated by various alkalis. Journal of the American Ceramic Society, 86(12): 2148-2153. https://doi.org/10.1111/j.1151-2916.2003.tb03623.x

[24] Wang, S.D., Scrivener, K.L. (1995). Hydration products of alkali activated slag cement. Cement and Concrete Research, 25(3): 561-571. https://doi.org/10.1016/00088846(95)00045-E 